\title{
Balkan Medical Journal and Legal Regulation
}

Balkan Medical Journal, the official university/academic journal of Trakya University Faculty of Medicine, is under the ownership of the deanery of the faculty and aims to propagate the current medical scientific knowledge in the Balkan region. The rectorate of Trakya University logistically supports the journal. On the other hand, the editor-in-chief is scientifically independent and cannot be pressurized or manipulated in any way regarding the scientific contents and operation of the journal. Nonetheless, the editor-in-chief has obligations toward the journal owner and editorial board. His/her editorial independence, rights, and responsibilities are aptly described and documented by the international scientific publishing communities. These include the editor's responsibilities, autonomy, and accountability of the journal's scientific content (1-5). Besides the editor-in-chief, the other editorial team members (managing, deputy, or assistant editors or any other editorial board member), the publisher, and the owner of a journal also have responsibilities, rights, and duties, which should all be documented in the journal legal regulation. Implementation of journal legal regulation will guarantee independent and responsible management of the journal, protect the editorial freedom, and ensure the team's transparency at work.

Since its establishment, the Balkan Medical Journal has aimed to select and publish distinctive, original articles in general medicine to contribute to universal scientific knowledge and to share its experience through educational activities for authors, reviewers, and editors (6). Despite the editor-in-chief and members of the editorial board getting replaced after their tenures, the Balkan Medical Journal's management has always believed that the fulfillment of its mission depends on the fundamental conditions of ethical values, respect, institutional attitude, and teamwork (7). The effort to maintain the editorial freedom has posed distinct challenges arising from regional dynamics in the Balkan region, as in any part of the world (7-10). Becoming an official member of important international publishing organizations, such as International Council of Medical Journal Editors (ICMJE), the World Association of Medical Editors (WAME), the Council of Science Editors (CSE), and the European Association of Science Editors (EASE), in addition to being formally recognized by the Committee on Publication Ethics (COPE), were all important milestones that have enabled Balkan Medical Journal to develop, maintain, and guarantee its editorial freedom (10).

A careful review of the literature reveals that the Balkan region has taken permanent steps towards institutionalization with the successful publication practices of journals. Croatian Medical Journal stands out as the most significant journal in this regard.
A paper by Marusic et al. (11) in 2005 demonstrates that the Croatians have combined the dynamics of four universities in their country to create a journal of national value and have shared their developmental experiences. Undoubtedly, the significant cornerstone in the success attained by the Croatians is the journal's legal regulation, which documents consensus.

For a journal to be successful in the international arena, reasonably organized managerial processes are required. Clear definitions of work packages, workflows, duties and responsibilities, and assignment and dismissal criteria are essential for the transparency of managerial processes. The journal's owner, editor-in-chief, editorial board, publisher, and authors effectively communicating with each other within the framework of rules will prevent chaotic and destructive conflicts that may harm the reputation and its mission. Furthermore, the inscription of such rules promotes scientific autonomy of the editor and prevents misuse of editorial freedom thereby resulting in the continuous success of a journal.

The efforts to establish a legal regulation, an agreement between the owner and the editor, and an ombudsman began approximately five years ago for Balkan Medical Journal. A draft text of legal regulation was submitted for discussion to the editorial board at that time. Intensive efforts have been carried out to achieve a certain degree of maturity. Since no other university/academic general medicine journal in Turkey is also indexed in internationally published SCI-E and Medline, it took time for all stakeholders to draft a consensus document. Thanks to the previous editor-in-chief of Balkan Medical Journal and the current vice-rector of Trakya University responsible for scientific journals (Cem Uzun), who has encouraged all editors of Trakya University journal to establish legal regulations, we have a transparent scientific publishing atmosphere to discuss, write, and own individual legal regulation for each journal. Throughout this process, the journal's management has endeavored to consult the opinions of the journal's owner and the university legal regulation committee to establish a legal regulation for the journal that is ethical, practical, sustainable, and conforms to the national laws and international scientific values. We believe the journal legal regulation, finalized in January 2019 and presented below, serves as a role model for all scientific circles and the Balkans and will contribute to the advancement of institutional scientific publications of medicine in the region. Nonetheless, this legal regulation is open to being updated and improved whenever needed, as our other policies. The journal's editorial board extends its gratitude to all current and past employees, the Dean's 
Office of the Faculty of Medicine of Trakya University, and to the current rectorate of Trakya University for their valuable contributions and encouragement to building the development of the journal legal regulation to protect editorial freedom and provide successful journal management of all Trakya University scientific journals.

\section{Mustafa İnan}

Deputy Editor, Balkan Medical Journal

Department of Pediatric Surgery, Trakya University School of Medicine, Edirne, Turkey

ORCID: orcid.org/0000-0001-8315-4328

\section{Hakan Erbaş}

Deputy Editor, Balkan Medical Journal

Department of Biochemistry, Trakya University School of Medicine, Edirne, Turkey

ORCID: orcid.org/0000-0002-7261-4170

\section{Zafer Koçak}

Editor-in-Chief, Balkan Medical Journal

Department of Radiation Oncology, Trakya University

School of Medicine, Edirne, Turkey

ORCID: orcid.org/0000-0003-1918-7795

\section{Cem Uzun}

Previous Editor-in-Chief, Balkan Medical Journal Department of Otolaryngology, Trakya University Faculty of Medicine, Edirne, Turkey ORCID: orcid.org/0000-0003-3233-7049

\section{REFERENCES}

1. Journal owners and editorial freedom. International Committee of Medical Journal Editors' Recommendations. Available at http://www.icmje.org/recommendations/ browse/roles-and-responsibilities/journal-owners-and-editorial-freedom.html (access: 04 February 2019).

2. The Relationship Between Journal Editors-in-Chief and Owners (formerly titled Editorial Independence). World Association of Medical Editors' policies. Available at http://wame.org/editorial-independence (access: 04 February 2019).

3. CSE's White Paper on Promoting Integrity in Scientific Journal Publications. Council of Science Editors' policies. Available at https://www.councilscienceeditors.org/ resource-library/editorial-policies/white-paper-on-publication-ethics/ (access: 04 February 2019).

4. A Short Guide to Ethical Editing for New Editors. COPE Guidelines. Available at https://publicationethics.org/files/A_Short_Guide_to_Ethical_Editing.pdf (access: 04 February 2019).

5. WAME Professionalism Code of Conduct. World Association of Medical Editors' policies. Available at http://wame.org/wame-professionalism-code-of-conduct (access: 04 February 2019).

6. Uzun C, Inan M, Caliyurt O. A distinct Gateway to Science in Balkans: Balkan Medical Journal. Eur Sci Editing 2015;41:11-3.

7. Uzun C. Improving your journal: A teamwork experience of a small medical journal. Presented at the 14th EASE Conference, Bucharest, 10 June 2018. Abstract available at http://www.ease.org.uk/ease-ev ents/14th-ease-conference-bucharest-2018/ programme-2018/ps5improvingyourjournal/ (access: 04 February 2019).

8. Koçak Z, Ulugöl A. History of Balkan Medical Journal: Road to High-Impact Journal. Balkan Med J 2018;35:1-7.

9. Koçak Z, İnan M, Süt N. Contribution of Balkan Medical Journal to the development and dissemination of medical science in the Balkans. Balkan Med J 2018;35:223-4.

10. Uzun C. Balkan Medical Journal is now a member of Committee on Publication Ethics. Balkan Med J 2013;30:349.

11. Marusic M, Bosnjak D, Rulic-Hren S, Marusic A. Legal regulation of the Croatian Medical Journal: model for small academic journals. Croat Med J 2003;44:663-73. 


\section{BALKAN MEDICAL JOURNAL - LEGAL REGULATION}

\section{CHAPTER ONE}

\section{Purpose, Scope, Basis, and Definitions}

\section{Purpose}

ITEM 1- (1) The purpose of this legal regulation is to establish the principles for the rules, duties and work processes constituted for the publication of the Balkan Medical Journal ("the Journal") and the basis for the Journal's publication policies.

\section{Scope}

ITEM 2- (1) The scope of this legal regulation includes the principles for the rules, duties and work processes constituted for the publication of the Journal and the basis for its publication policies.

\section{Basis}

ITEM 3- (1) This legal regulation has been prepared based on the provisions of the Regulation on Publications Exclusive of Course Books Used in Universities, Duplicates and Auxiliary Books, drafted in accordance with Items 14 and 48 of the Higher Education Code numbered 2547 and its relevant provisions.

\section{Definitions}

ITEM 4- (1) In this legal regulation:

a) Advisory board: Refers to the group that advises on publishing policy as necessary.

b) Associate editor: Refers to persons responsible for the Journal correspondence and publications related to their fields of expertise.

c) Assistant associate editor: Refers to persons responsible for the Journal correspondence and publications related to their fields of expertise.

d) Biostatistics editor: Refers to the editor responsible for all statistical checks and arrangements of research papers published in the Journal.

e) Deputy editor: Refers to persons responsible for the correspondence and publications of the Journal related to their field of expertise who are authorized to act in the absence of the Editorin-Chief.

f) Editorial board: Refers to the group chaired by the Editorin-Chief and consisting of the Journal's deputy editors, associate editors, assistant associate editors, biostatistics editor, editor of ethics and web page editor.

g) Editor-in-Chief: Refers to the person responsible for all managerial, correspondence and publication works of the Journal.

h) Ethics editor: Refers to the Journal's ethics consultant. i) Honorary editor: Refers to an individual selected from the former Journal editors-in-chief.

j) International publishing organizations: Refers to respectable publishing organizations such as EASE (European Association of Science Editors), WAME (World Association of Medical Editors), ICMJE (International Committee of Medical Journal Editors), COPE (Committee on Publication Ethics) and CSE (Council of Science Editors) that are significant to the Journal's advancement, and of which the Journal and/or its editors are members and follow their principles.

k) Journal: Refers to the Balkan Medical Journal.

1) Journal's Owner: Refers to the Dean of the School of Medicine at Trakya University.

m) Publishing house: Refers to the company tasked with the arrangement, preparation, and printing of the Journal's papers.

n) Reviewer: A scientist and field expert assigned by the editorial board members to scientifically evaluate papers submitted to the Journal.

o) Secretary: Refers to the person or persons who manage official correspondence, maintain records, register meeting reports, send items to the editorial board for review, and assist the Editor-in-Chief and the publication committee.

p) Submission system: Refers to the online accessible interface for uploading articles submitted to the Journal.

r) Web page editor: Refers to the person responsible for the design and management of the Journal's website.

\section{CHAPTER TWO}

\section{Duties, Responsibilities, and Assignments}

ITEM 5- (1) The Balkan Medical Journal is a peer-reviewed international academic Journal of general medicine published in English. The Journal is published in six issues annually. The Journal assesses and publishes eligible scientific research papers, compilations, case presentations, contributions comprising individual clinical and technical experimentations, brief papers with preliminary study results, clinical images, editorial letters, publication, and book introductions.

\section{Journal's Owner}

ITEM 6- (1) Refers to the Dean of the School of Medicine at Trakya University and is the person responsible for the publication of the Journal. The Journal's Owner accepts and supports the independence, dignity and scientific responsibility of the Editor-in-Chief.

a. Duties:

1. The Journal's Owner is responsible for completing the legal procedures necessary for the Journal to operate. 
2. The Owner is the sole authority for the Journal's financial affairs The Owner is also responsible for the Publisher tender and for attaining membership in international publishing organizations (EASE, CSE and COPE) on behalf of the Journal and/or the Editor-in-Chief.

3. The Owner selects the Editor-in-Chief from the full-time teaching staff under the respective Dean's Office in line with the criteria specified in Item 7-1a. The new Editor-in-Chief is assigned at least 30 days before the expiration of the previous Editor-inChief's term of office.

4. In the event that the Journal is delisted from an international index and/or the Editor-in-Chief is charged with proven ethical or disciplinary charges, the Owner shall dismiss the Editor-in-Chief from office.

5. The Owner shall assess the Journal's annual evaluation reports prepared by the Editor-in-Chief.

6. The Owner shall provide the fundamental conditions and support for the unbiased and independent operation of the Journal's Editor-in-Chief and the editorial board.

7. The Owner shall provide the offices, meeting halls and other work areas for the Journal's managerial and publishing activities, the editorial board's assessment and consultation activities, and any other requests in this regard.

8. The Owner shall assign a secretary to carry out the secretarial duties.

9. The Owner shall also provide support for the Editor-in-Chief and/or editorial board assigned by the Editor-in-Chief to attend important meetings on publishing activities.

\section{Editor-in-Chief}

ITEM 7- (1) The Editor-in-Chief is responsible for all correspondence and publication works of the Journal. The Editorin-Chief is scientifically independent. The Editor-in-Chief shall not be pressured or manipulated in any way with respect to the Journal's scientific contents and operation.

(2) The Editor-in-Chief has the sole authority (except for the Honorary editor) for the establishment and selection of all rules. Upon each assignment of a new Editor-in-Chief, the editorial board's term of office shall be deemed expired. The Editor-in-Chief's term is four years and can only be assigned for two subsequent terms.

\section{a. Qualities and duties:}

1. Full-time academic staff;

2. At least three years of work experience in a Journal indexed in "Science Citation Index Expanded;"

3. "Web of Science" $\mathrm{h}$ factor of at least 10 and at least 20 original articles published in such indexes, as well as over 200 references;

4. No disciplinary charges except for warnings and/or reprimands; 5. To select and assign the subordinate editors forming the editorial board of the Journal (deputy editors, associate editors, assistant associate editors, biostatistics editor and web page editor) in accordance with the criteria defined herein and to notify the Journal's Owner;

6. To ensure that at least one-third of the previous editors are present in the new editorial board to ensure smooth work flow and maintain corporate memory;
7. To recommend and assign an honorary editor based on editorial board discussion and approval by at least two-thirds of the board, and to notify the Journal's Owner of the assignment;

8. To decide on the final versions of papers;

9. To ensure seamless communication between the Journal's authors and its readers; to evaluate scientific developments, opinions and discussions in scientific and ethical ways, and to present reliable and verifiable knowledge to the Journal and to the scientific world;

10. To implement all measures to ensure that the editorial board carries out all its duties and responsibilities; to dismiss members of the editorial board who fail to perform their duties before their term expires; and to notify the Dean's Office of such dismissals along with the editorial board's opinions about the failure/ dismissals;

11. To issue annual activity reports and to hold a minimum of one meeting per year with the Journal's Owner;

12. To ensure the timely printing of the Journal.

b. The fundamental rules and principles to be followed by the Editor-in-Chief and the editorial board shall be implemented as per the following guidelines:

1. Code of Conduct and Best Practice Guidelines for Journal Editors and Short Guide to Ethical Editing for New Editors, defined by the Committee on Publication Ethics (COPE);

2. Golden Rules for Scholarly Journal Editors, defined by the European Association of Science Editors (EASE);

3. Syllabus for Prospective and Newly Appointed Editors, defined by the World Association of Medical Editors (WAME);

4. White Paper on Promoting Integrity in Scientific Journal Publications, 2012 Update, defined by the Council of Science Editors (CSE); and

5. International Standards for Editors (Kleinert \& Wager, 2011).

\section{Deputy Editors}

ITEM 8- (1) Refers to persons who are members of the editorial board and are authorized to manage editorial board meetings in the absence of the Editor-in-Chief. There shall be between three and six deputy editors. The term of office is two years. The Editorin-Chief may extend an expired term of office by notifying the Journal's Owner.

a) Qualities and duties:

1. At least two years' work experience with the Journal's editorial board;

2. "Web of Science" $\mathrm{h}$ factor of at least eight and at least 15 articles published in such indexes, as well as over 150 references;

3. No disciplinary charges except for warnings and/or reprimands; 4. To plan and implement the current and future state of the Journal alongside the Editor-in-Chief and to operate with authorization for specific works.

\section{Associate Editors}

ITEM 9- (1) Refers to persons responsible for the correspondence and publications in the Journal related to their fields of expertise. The term of office is two years. The Editor-in-Chief may extend an expired term of office by notifying the Journal's Owner. 


\section{a. Qualities and duties:}

1. "Web of Science" $\mathrm{h}$ factor of at least six and at least 10 articles published in such indexes, as well as over 100 references;

2. No disciplinary charges except for warnings and/or reprimands; 3. To prepare the Journal's writing rules, updating them as necessary; to check compliance of submissions against the Journal's writing rules;

4. To perform editorial evaluation of papers; submit opinions to the editorial board; discuss each issue in the editorial board; and to ensure papers are in line with the editorial board's majority vote;

5. To request removal from an assessment of a paper in the event of any conflict of interest or bias;

6. To strive for the advancement and promotion of the Journal in any and all platforms;

7. To strive to obtain quality papers and to advise the Editor-inChief on matters deemed beneficial to the Journal.

\section{Assistant Associate Editors}

ITEM 10- (1) Refers to persons selected by the Editor-in-Chief with competence in their field to be trained for the Journal's future operations. These persons are responsible for the correspondence and publications in the Journal related to their fields of expertise. The term of office is two years. The Editorin-Chief may extend an expired term of office by notifying the Journal's Owner.

a. Qualities and duties:

1. "Web of Science" h factor of at least two and at least five articles published in such indexes as well as over 20 references;

2. No disciplinary charges except for warnings and/or reprimands;

3. To perform the editorial evaluation of papers, submit opinions to the editorial board; discuss each issue in the editorial board; and to ensure papers are in line with the editorial board's majority vote;

4. To request removal from an assessment of a paper in the event of any conflict of interest or bias;

5. To strive for the advancement and promotion of the Journal in any and all platforms;

6. To strive to obtain quality papers and to advise the Editor-inChief on matters deemed beneficial to the Journal.

\section{Other Journal Editors}

ITEM 11- (1) Other Journal editors refers to the roles of biostatistics editor, ethics editor, web page editor, and honorary editor. These individuals are selected from a group of academics with no established ethical or disciplinary charges. The term of office is two years and there may be one or more terms. The Editorin-Chief may extend an expired term of office.

\section{a. Duties:}

1. Biostatistics editor: to conduct the statistical assessment of papers to be published in the Journal and to supervise the compliance of papers with international publication guidelines;

2. Ethics editor: to submit opinions on ethical issues and complaints and to direct and develop the Journal's ethics policy; 3. Web page editor: to carry out the design and management of the Journal's website;
4. Honorary editor: to advise on Journal policies.

\section{Editorial Board}

ITEM 12- (1) Refers to the board comprised of the Editorin-Chief, deputy editors, associate editors, assistant associate editors, biostatistics editor, ethics editor, and the Journal's web page editor. The board gathers once a week and is chaired by the Editor-in-Chief. Members who are unable to attend a meeting may notify the board of their opinions via e-mail to the Journal's secretary.

(2) While the Editor-in-Chief has the final word, he or she presents any issues related to the Journal to the editorial board for discussion.

(3) Upon failure to attend three consecutive meetings for any reason without a notifying excuse, editorial board members employed at Trakya University shall be dismissed from the editorial board. Upon failure to attend four consecutive meetings relating to the initial evaluation of papers assigned to them for any reason without notifying excuse, members who are not employed at Trakya University shall be dismissed from the editorial board. If required, a replacement will be assigned in line with the appropriate method.

(4) All editorial board staff members shall read the documents prepared by international publishing organizations and institutions on which the publishing policies of Balkan Medical Journal are based. The Editor-in-Chief will provide these before staff members take office. Furthermore, staff members will adhere to the principles and rules defined in these documents during their respective terms. The Editor-in-Chief will supervise adherence to these fundamental rules.

(5) The editorial board shall rule on whether a paper is to be published according to the opinions of the editorial board member following the paper. However, the final authority to rule rests with the Editor-in-Chief. The editorial board is also responsible for the processes of paper evaluation, consultancy, preparation for printing, pre-printing checks and changes in fundamental properties prior to printing the Journal.

(6) Editorial board members who are willing to quit their duty shall submit a letter of resignation to the Editor-in-Chief.

(7) If approved by the Editor-in-Chief, letters of resignation shall be directed to the Journal's Owner.

\section{Advisory Board}

ITEM 13- (1) The advisory board is comprised of national and international academics who have global influence. The number of reviewers may range from 15 to 30 . The members of this board shall serve as advisors to the Editor-in-Chief with controversial papers or when an advisor cannot be found. The members are selected by the editorial board. They may resign from the position voluntarily.

\section{Journal Secretary}

ITEM 14- (1) The Journal secretary is assigned by the Journal's Owner. The secretary carries out official correspondence, maintain Journal records, records meeting notes and distributes meeting reports to editorial board members. She/ 
he also manages the Journal's official e-mail account (info@, balkanmedicaljournal.org) and assists the Editor-in-Chief as well as the editorial board.

\section{CHAPTER THREE}

\section{Journal Operation}

\section{The responsibilities of the Editor-in-Chief and members of the editorial board within the scientific publishing process.}

ITEM 15- (1) The Editor-in-Chief and the editorial board shall actuate the Journal's scientific publication processes within the framework of established publishing policies. For this purpose:

a. The Journal's purposes, contents, and publication policies shall be set jointly by the Editor-in-Chief and the editorial board. The Journal's Owner shall be notified of such decisions.

b. They shall ensure the on-time publication of the Journal and its superior scientific qualities.

c. They shall ensure continuity and compliance with international standards in all affairs and activities.

d. They evaluate submitted papers on time, rule on conformance with the fields relevant to the Journal's areas of general medicine and worth reviewer consideration assign appropriate papers to reviewers with proven academic competence relevant to the content as per international standards and follow and finalize the entire publication process according to the rules of the publication process. They will closely monitor referees and assign replacements when necessary to avoid delays.

e. During the course of such processes, they shall act with academic courtesy towards authors, undertaking an educational and instructive approach.

f. They ensure each step of these processes is recorded and archived.

g. They relay the reviewers' criticisms to the authors and ensure the papers are corrected and their quality is increased while also evaluating grammar and intelligibility.

h. They accept or reject paper submissions according to the criticism and advice received, and/or change categories as necessary.

i. They check the first and final print of all papers after typesetting and monitor the publication preparation team's work.

j. They ensure that any topic or author in the current and past issues of the Journal can be searched via the Journal's website and web page.

$\mathrm{k}$. In the event that any submitted paper, according to the reviewers' notices and editorial board ruling, creates any type of controversy, the editorial board shall exchange opinions internally or consult the Ethics editor to rule in accordance with COPE rules. 1. They act in accordance with COPE guidelines upon detection or suspicion of any breach of the publication ethics. m. Part of the technical duties may be contracted to a publishing organization or a professional team.

n. In particular, the official records, correspondence and papers kept by the Journal's secretary shall be maintained for a period of five years. After a five-year storage period, these documents shall be stored indefinitely in a Journal room in the diaconate building with which the Journal is associated. If automatic backup is unavailable in the article upload system, all data in digital media shall be backed up and transmitted to the Dean's Office by the respective IT company quarterly.

o. Members of the editorial board cannot take part in processes and decisions related to their own papers, their immediate relatives' papers, papers by academic members of the same department, or papers where there is likely to be a conflict of interest with the author-researcher. In such cases, the relevant decisions shall be rendered by the other editorial board members and ultimately by the Editor-in-Chief.

p. The authors bear full scientific and legal responsibility for published papers. None of the publications are binding for Trakya University or the Journal and they cannot be construed as representing Trakya University's official opinions. However, the editorial board shall keep track of papers following publication as necessary. The board shall ensure that the appropriate papers are withdrawn and/or corrected as necessary. For this purpose, the rules of COPE or similar organizations shall be used as criteria.

q. No payments shall be rendered to the Editor-in-Chief or other editorial board members.

\section{Reviewers}

ITEM 16- (1) Reviewers may be assigned from among experts outside the editorial board to evaluate papers and to support the Editorial Board. The list of reviewers shall be published online on the Journal's web page and in the final issue of each year.

a. Reviewers shall be determined by the editorial board in consideration of their fields of research and experience in domestic and international studies. Reviewers must be experts in the fields of the papers they evaluate.

b. Together with the Editor-in-Chief, the relevant editorial board member will decide on the number of reviewers and evaluation by additional reviewer(s) as necessary for each paper. Each paper must be evaluated by at least two reviewers. Both reviewers cannot be those preferred by the author.

c. The Editor-in-Chief may decide to increase the number of or dismiss reviewers as necessary. However, the editorial board members may find other reviewers as necessary.

d. A reviewer's response time and the scientific level of critique shall be considered in the decision to assign another paper to the same reviewer. It is the duty of the respective member of the editorial board to maintain records of papers assigned to reviewers, the reviewers' response time and the numbers in digital media.

e. Reviewers are required to notify the Journal of their acceptance or refusal to advise on the assigned paper within seven days at most and to transmit a report on the paper to the respective editorial board member within three weeks. 


\section{CHAPTER FOUR}

\section{Effectiveness and Enforcement}

\section{Effectiveness}

ITEM 17- (1) This legal regulation shall take effect upon approval by the Senate of Trakya University.

\section{Enforcement}

ITEM 18- (1) The provisions of this legal regulation shall be enforced by the Dean of the School of Medicine.

\section{Provisional Items}

ITEM 1- (1) The Editor-in-Chief in office on the date of the approval of this legal regulation shall be deemed assigned to the office for the first time upon approval of this legal regulation.

ITEM 2- (1) The terms of editorial board members, except for the Editor-in-Chief, shall be deemed expired upon approval of this legal regulation. 